\title{
RKIP is decreased in laboring myometrium and modulates inflammation-induced pro-labor mediators
}

\author{
Martha Lappas \\ Mercy Perinatal Research Centre, Mercy Hospital for Women, Heidelberg, Victoria, Australia and Obstetrics, \\ Nutrition and Endocrinology Group, Department of Obstetrics and Gynaecology, University of Melbourne, \\ Melbourne, Victoria, Australia
}

Correspondence should be addressed to M Lappas; Email: mlappas@unimelb.edu.au

\begin{abstract}
Nuclear factor-kappa B (NF-кB)-induced inflammation plays a central role in the terminal process of human labor and delivery. Our previous studies show that IL1B induces NF-кB signaling through extracellular signal-regulated kinase (ERK; official gene symbol MAPK1), whereas TNF induces NF-кB-driven transcription of pro-labor mediators via an MAPK1-independent mechanism. Raf kinase inhibitor protein (RKIP) negatively regulates inflammation by inhibiting NF-кB activation directly or indirectly by inhibiting MAPK1. The role of RKIP in the processes of human labor and delivery is not known. The present study was performed to investigate the expression of RKIP in laboring and non-laboring human myometrium and determine the effect of siRNA knockdown of RKIP (siRKIP) on pro-labor mediators in human myometrial primary cells. Term labor was associated with a decrease in RKIP expression.

Furthermore, RKIP expression was decreased in myometrial cells treated with IL1B and TNF, two likely factors contributing to preterm birth. The effect of siRKIP in primary myometrial cells was a significant augmentation of IL1B- and TNF-induced CXCL1 and CXCL8 mRNA abundance and secretion; PTGS2 mRNA levels and prostaglandin PGF $_{2 \alpha}$ release and MMP9 mRNA abundance and pro-MMP9 secretion. There was no effect of siRKIP on MAPK1 activation. On the other hand, RKIP knockdown was associated with increased activation of NF-KB RELA in the presence of IL1B and TNF. In conclusion, in human primary myometrial cells, RKIP negatively regulates IL1B- and TNF-induced expression and or secretion of pro-inflammatory and pro-labor mediators by inhibiting NF-кB RELA activation.

Reproduction (2017) 153 545-553
\end{abstract}

\section{Introduction}

Preterm birth is a global health issue (Beck et al. 2010). It is estimated that 15 million babies are born prematurely every year (Blencowe et al. 2012). Alarmingly, over a third of the world's annual 3.1 million neonatal deaths are attributable to complications associated with preterm birth (Blencowe et al. 2012). Further, there are serious long-term consequences for those who survive including visual and hearing impairments, neurodevelopmental disabilities and chronic lung disease (Saigal \& Doyle 2008). Spontaneous preterm birth accounts for approximately $70 \%$ of all preterm births with approximately $40-50 \%$ due to preterm labor with cervical dilation (with intact membranes) and $25-40 \%$ due to preterm premature rupture of the membranes (Goldenberg et al. 2008). There are no effective treatments that can stop preterm labor (Barros et al. 2010, Norman \& Shennan 2013). Thus, to develop clinically useful interventions and improve neonatal outcome, elucidation of the mechanisms involved in the initiation and progression of labor is essential.
Infection and inflammation are commonly associated with preterm labor and thought to have a driving role in initiating uterine contractions (Romero et al. 2007, Christiaens et al. 2008a). Activation of maternal immune system leads to a massive influx of leukocytes in the uterus, myometrium and fetal membranes through the release of chemokines such as chemokine (C-X-C motif) ligand 1 (CXCL1) and CXCL8 (Thomson et al. 1999, Osman et al. 2003). Infiltrating leukocytes augment the pro-inflammatory microenvironment through the release pro-inflammatory cytokines, such as interleukin 1 beta (IL1B) and tumor necrosis factor alpha (TNF), to amplify or initiate the process of parturition. These cytokines then promote the synthesis of contractions-associated proteins such as prostaglandin-endoperoxide synthase 2 (PTGS2), which is responsible for the synthesis of prostaglandins (Bartlett et al. 1999, Erkinheimo et al. 2000, Rauk \& Chiao 2000) and the extracellular matrix (ECM) remodeling enzyme matrix metalloproteinase 9 (MMP9) (Roh et al. 2000).

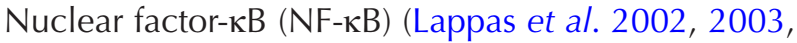
Lindstrom \& Bennett 2005, Lappas \& Rice 2007) and 
rapidly accelerated fibrosarcoma 1 (RAF1) (Lappas $2016 b)$ regulate the genes involved in the terminal effector pathways of human labor and delivery. In human myometrium, IL1B and TNF can induce NF- $\mathrm{kB}$ RELA activation to induce the expression of pro-inflammatory cytokines and PTGS2 (Khanjani et al. 2012, Liong \& Lappas 2015). Likewise, RAF1, a principle component of the extracellular signal-regulated kinase (ERK; official gene symbol MAPK1) pathway, is increased in laboring myometrium and in response to the proinflammatory cytokines IL1B and TNF (Lappas 2016b). RAF1, like NF- $\mathrm{kB}$, is involved in the genesis of pro-labor mediators induced by inflammation (Lappas 2016b). Specifically, IL1B induces the expression and secretion of pro-inflammatory cytokines and chemokines, PTGS2 expression and prostaglandin secretion in primary myometrial cells through the RAF1-MAPK1-NF-kB RELA signaling pathway. TNF, on the other hand, induces the expression and secretion of pro-inflammatory cytokines and chemokines, PTGS2 expression and prostaglandin release through the RAF1-NF-kB signaling pathway via a MAPK1-independent mechanism.

Raf kinase inhibitor protein (RKIP, also known as phosphotidylethanolamine-binding protein-1 (PEBP1)) is a ubiquitously expressed cytosolic $\sim 21 \mathrm{kD}$ protein. RKIP was first shown to function as a negative regulator of the MAPK1 cascade initiated by RAF1 (Yeung et al. 1999, 2000). RKIP, however, can also act as a scaffold protein that can antagonize NF- $\mathrm{kB}$ in response to stimulation with TNF and IL1B and may act upstream of NF- $\mathrm{KB}$ to inhibit one or more kinases including the IKK complex (Yeung et al. 2001, Tang et al. 2010). RKIP is involved in numerous cellular processes such as cell proliferation, angiogenesis, differentiation and apoptosis (Al-Mulla et al. 2013). Functional studies using both gain-of-function and loss-of-function approaches have demonstrated that RKIP also regulates inflammation. For example, overexpression of RKIP in primary rheumatoid fibroblast-like synoviocytes significantly decreased TNFstimulated expression of MMP1, MMP3, IL6 and IL8 (Schuierer et al. 2006). Furthermore, upregulation of RKIP in human salivary gland epithelial cells decreased proinflammatory cytokines and chemokines concomitant with decreased NF-KB activation (Sisto et al. 2014). Conversely, silencing of RKIP expression dramatically increased the expression of MMPs including MMP9 in a number of different cancer cell lines (Beshir et al. 2010). Given its role in a wide variety of processes, RKIP has been implicated in a range of pathologies, including cancer, Alzheimer's disease and pancreatitis (Al-Mulla et al. 2013). There are, however, no studies on RKIP in human pregnant myometrium and its role in regulating inflammation.

The hypothesis to be tested is that RKIP expression is decreased in myometrium with human labor and mediators of preterm labor and inhibition of RKIP is associated with increased expression of pro-inflammatory and pro-labor mediators. The aims of this study were to (i) characterize the expression of RKIP in human myometrium from laboring and non-laboring women; (ii) determine the effect of pro-inflammatory cytokines on RKIP expression in cells isolated from the human myometrium; (iii) elucidate the effect of RKIP siRNA knockdown on inflammation-induced prolabor mediators in primary cells isolated from human myometrium and (iv) determine if RKIP regulates pro-labor mediators via MAPK1 and/or NF- $\kappa B$ RELAdependent mechanisms.

\section{Materials and methods}

\section{Tissue collection}

The Research Ethics Committee of Mercy Hospital for Women approved this study. Written, informed consent was obtained from all participating women. All tissues were obtained from women who delivered healthy, singleton infants. All tissues were brought to the research laboratory and processed within 15 min of the Caesarean delivery. Women with any underlying medical conditions such as diabetes, asthma, polycystic ovarian syndrome, preeclampsia and macrovascular complications were excluded. Additionally, women with multiple pregnancies, obese women and fetuses with chromosomal abnormalities were excluded.

Myometrium was obtained from consenting women at the time of term Caesarean section ( $\geq 37$-week gestation). Myometrial biopsies, obtained from the upper margin of the lower uterine segment incision during the Caesarean section, were collected from two groups of women: (i) pregnant women undergoing elective Caesarean section in the absence of labor ( $n=8$ patients; mean gestational age $39.4 \pm 0.3$ weeks) and (ii) pregnant women who were delivered during active labor; labor was defined as the presence of regular uterine contractions (every 3-4 min) resulting in cervical effacement and dilation ( $n=8$ patients; mean gestational age $39.8 \pm 0.2$ weeks). Indications for Caesarean section in the absence of labor were breech presentation and/or previous Caesarean section. Indications for Caesarean section in the laboring samples were for placenta praevia, fetal distress and delayed or failure to progress. There was no difference in maternal age and body mass index, parity or gestational age of the patients recruited. In the laboring group, none of the patients received any medications to augment or induce labor, and the average length of labor was $10 \mathrm{~h} \pm 6 \mathrm{~h} 40 \mathrm{~min}$. Tissue samples were fixed and paraffin embedded for immunohistochemical analysis or snapfrozen in liquid nitrogen and immediately stored at $-80^{\circ} \mathrm{C}$ for analysis by qRT-PCR and Western blot as detailed below.

\section{Primary myometrial cell culture}

Primary myometrial cells were used to investigate the effect of pro-inflammatory cytokines on RKIP expression and the effect of RKIP siRNA (siRKIP) and U0126 (MAPK1 inhibitor) on the expression of pro-labor mediators. Fresh myometrium was obtained from women who delivered healthy, singleton infants at term (37- to 41-week gestation) undergoing elective 
Caesarean section in the absence of labor. Cells were isolated and cultured as previously described (Lim et al. 2013a). Briefly, myometrium was minced and digested for $1 \mathrm{~h}$ in Dulbecco's Modified Eagle's Medium/Nutrient Mixture F-12 Ham (DMEM/F-12) with $3 \mathrm{mg} / \mathrm{mL}$ type 1 collagenase (Worthington Biochemical Corp., Lakewood, NJ, USA) and $80 \mu \mathrm{g} / \mathrm{mL}$ DNase 1 (Roche Diagnostics) at $37^{\circ} \mathrm{C}$. Cells were centrifuged at $400 \mathrm{~g}$ for $10 \mathrm{~min}$ and grown in DMEM/F-12 enriched with $10 \%$ heat-inactivated FCS (containing $100 \mathrm{U} / \mathrm{mL}$ penicillin $\mathrm{G}$ and $100 \mathrm{mg} / \mathrm{mL}$ streptomycin).

Transfection of primary myometrial cells was performed as previously described (Lim et al. 2016). Briefly, cells at approximately $50 \%$ confluence were transfected using Lipofectamine 3000 according to manufacturer's guidelines (Life Technologies). RKIP siRNA (siRKIP) and negative control siRNA (siCONT) were obtained from Ambion (Thermo Fisher Scientific). Cells were transfected with $50 \mathrm{nM}$ siRNA in DMEM/F-12 for $48 \mathrm{~h}$ followed by treatment with or without $1 \mathrm{ng} / \mathrm{mL}$ IL1B (PeproTech; Rocky Hill, NJ, USA) or $10 \mathrm{ng} / \mathrm{mL}$ TNF (PeproTech) with or without 10 $\mathrm{MM}$ BAY 11-7082 (Tocris; Minneapolis, MN, USA) or $5 \mu \mathrm{M} \cup 0126$ (Tocris) for $24 \mathrm{~h}$. Cells were collected and stored at $-80^{\circ} \mathrm{C}$ until assayed for mRNA expression by qRT-PCR as detailed below. Media was collected and stored at $-80^{\circ} \mathrm{C}$ until assayed for cytokine and prostaglandin release as detailed below. Cell viability was assessed by the 3-(4,5-dimethyl-2-thiazolyl)-2,5-diphenyl-2Htetrazolium bromide (MTT) proliferation assay. As previously reported, the response to IL1B and TNF between patients varied greatly (Lim et al. 2016). Thus, data are presented as fold change in expression relative to the expression level in the IL1B- or TNF-stimulated siCONT-transfected cells, which was set at 1. Experiments for each treatment were performed from myometrium obtained from five patients.

\section{NF-אB RELA luciferase assay}

A luciferase assay was utilized to determine possible interactions between RKIP and NF- $\mathrm{BB}$ RELA, as previously described (Lim et al. 2016). Primary myometrial cells, prepared as described previously, at approximately $70 \%$ confluence, were transfected with $0.75 \mathrm{ng}$ RELA reporter construct (Qiagen) using FuGENE HD transfection reagent (Promega). After $6 \mathrm{~h}$, cells were transfected with $50 \mathrm{nM}$ of siRKIP or siCONT (as detailed previously) for $48 \mathrm{~h}$. The medium was then replaced with DMEM/F-12 (containing 0.5\% BSA), with or without $1 \mathrm{ng} / \mathrm{mL}$ IL1B or $10 \mathrm{ng} / \mathrm{mL}$ TNF, and the cells were incubated at $37^{\circ} \mathrm{C}$ for an additional $20 \mathrm{~h}$. After final incubation, cells were harvested in lysis buffer, and luminescence activity was measured using a Luciferase Reporter Assay Kit (Life Research; Scoresby, Vic, Australia) and Renilla Luciferase Flash Assay Kit (Thermo Fisher Scientific) as instructed. The ratio of the firefly luciferase level to the Renilla luciferase level was determined and the results are expressed as a ratio of normalized luciferase activity. The experiments were performed from myometrium obtained from five patients.

\section{RNA extraction and quantitative RT-PCR (qRT-PCR)}

RNA extraction and qRT-PCR were performed as previously described (Lim et al. 2016). Briefly, total RNA was extracted from cells using TRIsure reagent according to manufacturer's instructions (Bioline; Alexandria, NSW, Australia). RNA concentration and purity were measured using a NanoDrop ND1000 spectrophotometer (Thermo Fisher Scientific). RNA $(0.2 \mu \mathrm{g})$ was converted to cDNA using the Tetro cDNA synthesis kit (Bioline) according to the manufacturer's instructions. The RT-PCR was performed using the CFX384 Real-Time PCR detection system (Bio-Rad Laboratories) using $100 \mathrm{nM}$ of predesigned and validated QuantiTect primers (Qiagen). Average gene $\mathrm{Ct}$ values were normalized against two housekeeping genes (lipoprotein receptor-related protein 10 (LRP10) and succinate dehydrogenase complex subunit A (SDHA)). Of note, there was no effect of experimental treatment on LRP10 or SDHA mRNA expression. Fold differences were determined using the comparative Ct method.

\section{Western blotting}

Western blotting was performed as previously described (Lim et al. 2016). Blots were incubated in $1 \mu \mathrm{g} / \mathrm{mL}$ mouse polyclonal anti-RKIP (WH0005037M2; Sigma-Aldrich), $1 \mu \mathrm{g} / \mathrm{mL}$ rabbit polyclonal anti-MAPK1 (sc-93; Santa Cruz Biotechnology) or $1 \mu \mathrm{g} / \mathrm{mL}$ mouse monoclonal antiphosphorylated MAPK1 (sc-7383; Santa Cruz Biotechnology) prepared in blocking buffer $(5 \%$ skim milk in TBS with $0.05 \%$ Tween20) for $16 \mathrm{~h}$ at $4{ }^{\circ} \mathrm{C}$. Membranes were viewed and analyzed using the ChemiDoc XRS system (Bio-Rad Laboratories). Semi-quantitative analysis of the relative density of the bands in Western blots was performed using Quantity One 4.2.1 image analysis software (Bio-Rad Laboratories). For the labor studies, RKIP protein expression was normalized to Ponceau S stain, as described previously (Lim et al. 2016); a section of the Ponceau S-stained membrane was chosen, which did not show variation with labor status.

\section{Enzyme immunoassays}

The release of CXCL8 was performed using CytoSet sandwich ELISA according to the manufacturer's instructions (Life Technologies). The limit of detection of the CXCL8 assays was $12 \mathrm{pg} / \mathrm{mL}$. The release of CXCL1 was performed by sandwich ELISA from R\&D Systems according to the manufacturer's instructions. The limit of detection of the CXCL1 assay was $40 \mathrm{pg} / \mathrm{mL}$. The release of $\mathrm{PGF}_{2 \alpha}$ into the incubation medium was assayed using a commercially available competitive enzyme immunoassay kit according to the manufacturer's specifications (Kookaburra Kits from Sapphire Bioscience, Redfern, NSW, Australia). The limit of detection of the $\mathrm{PGF}_{2 \alpha}$ assay was $30 \mathrm{pg} / \mathrm{mL}$. For all assays, the interassay and intraassay coefficients of variation $(\mathrm{CV})$ were less than $10 \%$.

\section{Gelatin zymography}

Incubation media was also collected, and assessment of MMP9 was performed by gelatin zymography as previously described (Lim et al. 2013b). Proteolytic activity was visualized as clear zones of lysis on a blue background of undigested gelatin. Gels were scanned using a ChemiDoc XRS system (Bio-Rad Laboratories), inverted and densitometry was performed using Quantity One image analysis software (Bio-Rad Laboratories). 


\section{Statistical analysis}

All statistical analyses were undertaken using GraphPad Prism (GraphPad Software). For two sample comparisons, either a paired or unpaired Student's t-test was used to assess statistical significance between normally distributed data; otherwise, the nonparametric Mann-Whitney $U$ (unpaired) or the Wilcoxon (matched pairs) tests were used. For all other comparisons, the homogeneity of data was assessed by the Bartlett's test using a one-way ANOVA (with LSD post hoc testing to discriminate among the means). Statistical significance was ascribed to a $P$ value $<0.05$. Data were expressed as mean \pm S.E.M.

\section{Results}

\section{RKIP is decreased in laboring myometrium}

Myometrium was obtained from women at term Caesarean section in the absence of labor (term no labor; $n=8$ patients) and after spontaneous labor onset (term in labor; $n=8$ patients). RKIP mRNA (Fig. 1A) and protein (Fig. 1B) expression was also significantly lower in laboring myometrium when compared to nonlaboring samples.

The pro-inflammatory cytokines IL1B and TNF were assessed as these have been shown to induce preterm birth in vivo (Sadowsky et al. 2006). As shown in Figure 1, incubation of myometrial cells with IL1B or TNF significantly decreased RKIP mRNA expression (Fig. 1C).

\section{RKIP regulates chemokines in primary myometrium cells}

The next aim was to determine if RKIP regulates the genesis of pro-inflammatory and pro-labor mediators induced by IL1B and TNF. For these studies, primary myometrial cells isolated from fresh myometrial tissue were used, and knockdown of RKIP was performed by siRNA. The efficacy of transfection was analyzed by qRT-PCR and Western blotting (Supplementary Fig. 1, see section on supplementary data given at the end of this article). When compared to siCONT-transfected cells, RKIP siRNA transfection resulted in $85 \%$ decrease in RKIP mRNA expression and $75 \%$ decrease in RKIP protein expression. There was no effect of siRKIP on cell viability as determined by MTT assay.

For all subsequent experiments, after siRNA transfection, cells were treated with the proinflammatory cytokines IL1B or TNF. The effect of siRKIP on the expression and release of chemokines in the presence of IL1B or TNF is shown in Figure 2. In siCONTtransfected cells, CXCL1 and CXCL8 mRNA abundance and the release of CXCL1 and CXCL8 were significantly increased by treatment with IL1B (Fig. 2A, B, C and D) or TNF (Fig. 2E, F, G and H). The effect of siRKIP was a significant augmentation of IL1B- and TNF-induced
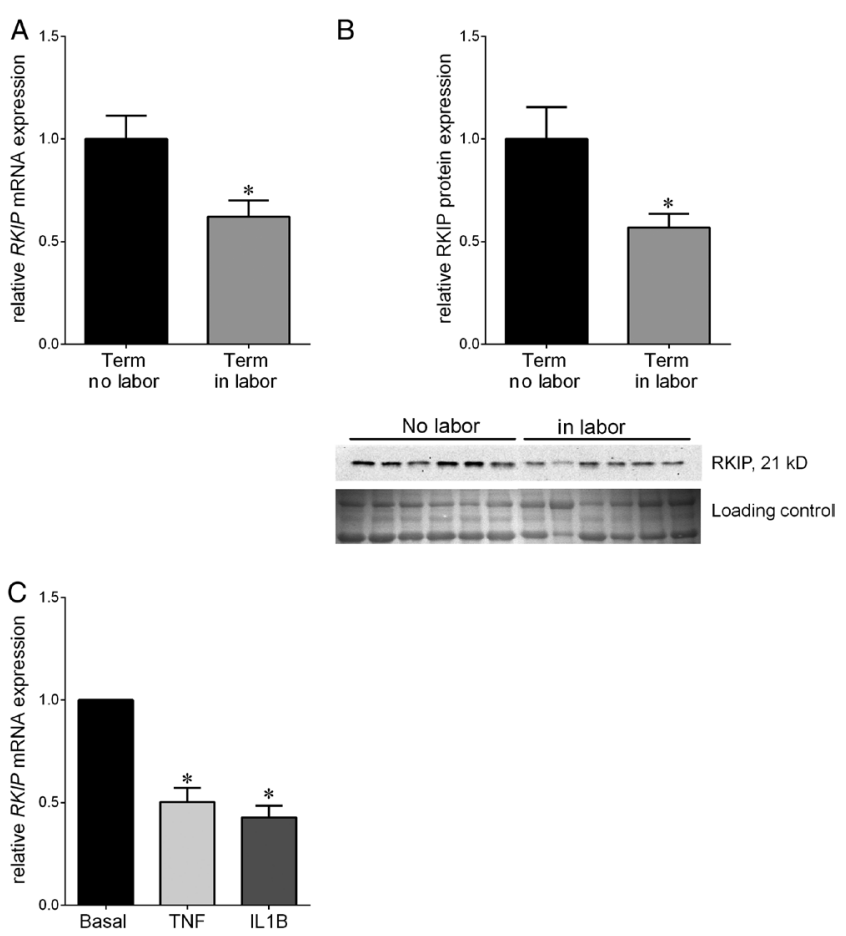

Figure 1 RKIP is increased in laboring myometrium. (A and B) Human myometrium was obtained from non-laboring and laboring women at term Caesarean section ( $n=8$ patients per group). (A) RKIP mRNA abundance was analyzed by qRT-PCR and the fold change was calculated relative to the no labor group. Data are displayed as mean \pm S.E.M. ${ }^{*} P<0.05$ vs no labor (Student's $t$-test). (B) RKIP protein expression was analyzed by Western blotting, and Ponceau S stain was used as a loading control. The fold change was calculated relative to the no labor group. Data are displayed as mean \pm S.E.M. ${ }^{*} P<0.05$ vs no labor (Student's $t$-test). Representative Western blot from 6 patients per group is also shown. (C) Human primary myometrial cells were incubated in the absence or presence of $1 \mathrm{ng} / \mathrm{mL}$ IL1B or $10 \mathrm{ng} / \mathrm{mL}$ TNF for $20 \mathrm{~h}$ ( $n=5$ patients). RKIP mRNA expression was analyzed by qRT-PCR and the fold change was calculated relative to basal. Data are displayed as mean \pm S.E.M. $* P<0.05$ vs basal (one-sample $t$-test).

CXCL1 (Fig. 2A, B, E and F) and CXCL8 (Fig. 2C, D, G and $\mathrm{H}$ ) mRNA abundance and release. There was no effect of siRKIP on IL1B- or TNF-induced CCL2 or CCL3 mRNA expression or secretion (data not shown).

\section{RKIP regulates the $P T G S 2-$ prostaglandin pathway in primary myometrium cells}

Figure 3 demonstrates the effect of siRKIP on PTGS2 mRNA abundance and the secretion of $\mathrm{PGF}_{2 \alpha}$ in the presence of IL1B or TNF. Treatment with IL1B (Fig. 3A and B) or TNF (Fig. 3C and D) significantly increased PTGS2 mRNA expression and PGF $_{2 \alpha}$ release in siCONTtransfected myometrial cells. The effect of siRKIP was a significant amplification in IL1B- or TNF-induced PTGS2 mRNA expression and $\mathrm{PGF}_{2 \alpha}$ release. 

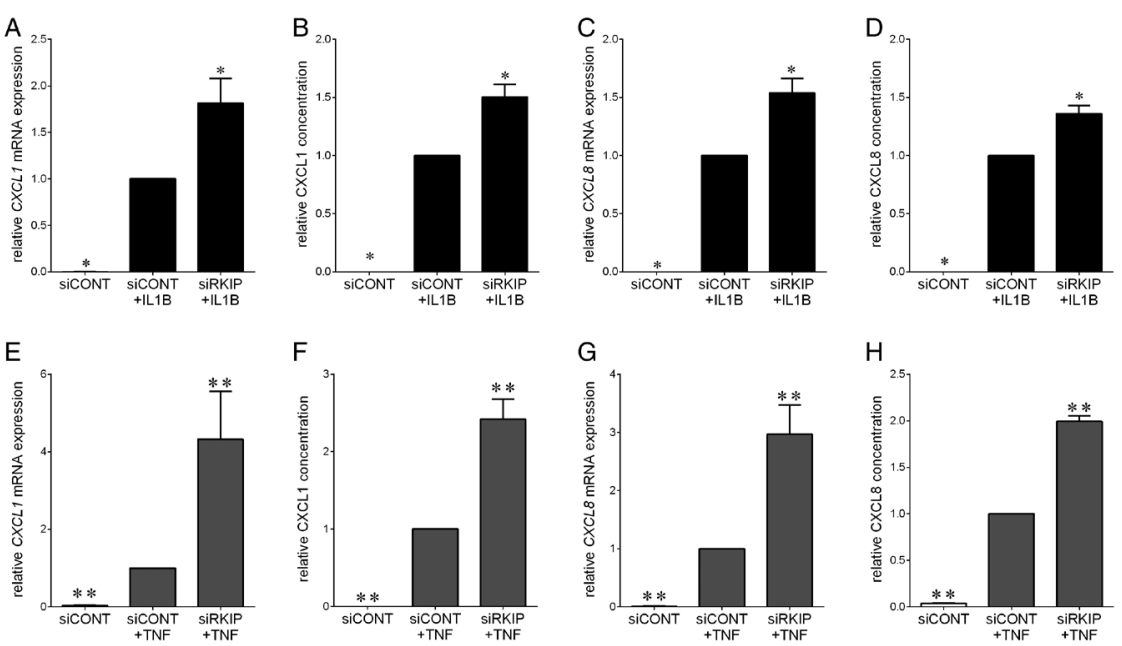

\section{RKIP regulates MMP9 expression in primary myometrium cells}

The effect of siRKIP on the ECM remodeling and degrading enzyme MMP9 in the presence of IL1B or TNF was also assessed and the data are presented in Figure 4. In siCONT-transfected cells, incubation with IL1B (Fig. 4A and B) or TNF (Fig. 4C and D) significantly increased MMP9 mRNA abundance and the expression of pro MMP9 in the incubation media. IL1B- and TNF-induced MMP9 mRNA abundance and proMMP9 secretion were further increased by transfection with siRKIP.

\section{RKIP regulates pro-inflammatory and pro-labor mediators via $N F-\kappa B$}

A luciferase assay was performed to determine the interaction between RKIP and NF-KB RELA. As expected, IL1B (Fig. 5A) and TNF (Fig. 6A) significantly increased RELA luciferase activity in siCONT-transfected myometrial cells. The effect of transfection with siRKIP was a significant augmentation of IL1B-andTNF-induced luciferase activity. Thus, the next aim was to determine
Figure 2 RKIP regulates chemokines in primary myometrium cells. Human primary myometrial cells were transfected with or without $50 \mathrm{nM}$ siRKIP or siCONT for $48 \mathrm{~h}$ and then treated with (A-D) $1 \mathrm{ng} / \mathrm{mL}$ IL1B or $(\mathrm{E}-\mathrm{H})$ $10 \mathrm{ng} / \mathrm{mL}$ TNF for an additional $20 \mathrm{~h}(n=5$ patients). (A, C, E, G) CXCL1 and CXCL8 mRNA abundance was analyzed by qRT-PCR and the fold change was calculated relative to IL1B- or TNF-stimulated siCONT-transfected cells. (B, D, F, H) CXCL1 and CXCL8 concentration in the incubation medium was assayed by ELISA. The fold change was calculated relative to IL1B- or TNF-stimulated siCONT-transfected cells. All data are displayed as mean \pm S.E.M. ${ }^{*} P<0.05$ vs IL1B-stimulated siCONT-transfected cells (oneway ANOVA); $* * P<0.05$ vs TNF-stimulated siCONT-transfected cells (one-way ANOVA).

whether RKIP regulates pro-inflammatory and pro-labor mediators through the NF-KB pathway. To test this, the pharmacological inhibitor of NF-kB, BAY 11-7082, was used. We have previously shown BAY 11-7082 inhibits the activation of NF-KB RELA in primary myometrial cells (Lim et al. 2013a). BAY 11-7082 significantly attenuated IL1B (Fig. 5B, C, D and E), and TNF (Fig. 6B, C, D and E) induced CXCL1 mRNA expression and release, PTCS2 mRNA abundance and $\mathrm{PGF}_{2 \alpha}$ secretion.

\section{RKIP does not regulate pro-inflammatory and pro-labor mediators via MAPK1}

The effect of siRKIP on MAPK1 activation was also assessed. For these studies, only IL1B was analyzed as TNF does not activate MAPK1 in primary myometrial cells (Lappas 2016b). As expected, in siCONT-transfected cells, IL1B significantly increased the phosphorylation of MAPK1 (Supplementary Fig. 2A). There was, however, no effect of siRKIP on phosphorylation of MAPK1. There was also no effect of the MAPK1 inhibitor U0126 on IL1B-induced pro-labor mediators in siRKIP-transfected cells (Supplementary Fig. 2B and C).
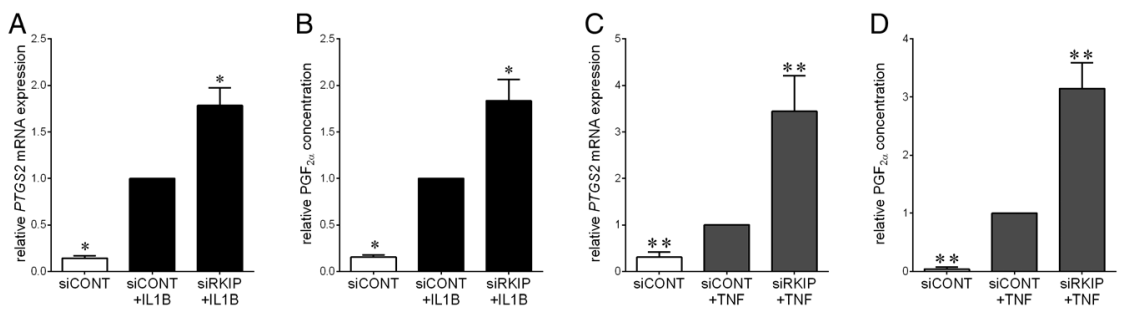

Figure 3 RKIP regulates the PTGS2-prostaglandin pathway in primary myometrium cells. Human primary myometrial cells were transfected with or without $50 \mathrm{nM}$ siRKIP or siCONT for $48 \mathrm{~h}$ and then treated with (A, B) $1 \mathrm{ng} / \mathrm{mL}$ IL1B or (C, D) $10 \mathrm{ng} / \mathrm{mL}$ TNF for an additional $20 \mathrm{~h}(n=5$ patients). (A, C) PTGS2 mRNA abundance was analyzed by qRT-PCR and the fold change was calculated relative to IL1B- or TNF-stimulated siCONT-transfected cells. (B, D) PGF $_{2 \alpha}$ concentration in the incubation medium was assayed by ELISA, and the fold change was calculated relative to IL1B- or TNF-stimulated siCONT-transfected cells. All data are displayed as mean \pm S.E.M. $* P<0.05$ vs IL1B-stimulated siCONTtransfected cells (one-way ANOVA); ${ }^{* *} P<0.05$ vs TNF-stimulated siCONT-transfected cells (one-way ANOVA). 

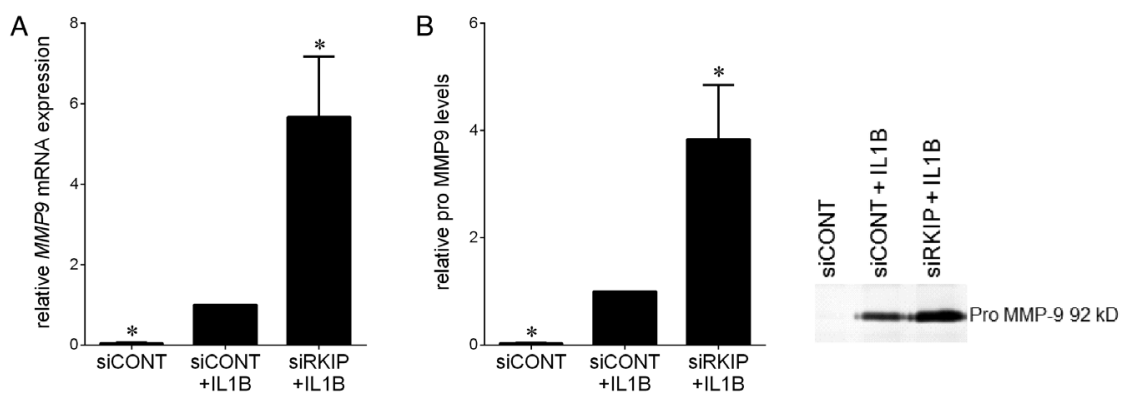

Figure 4 RKIP regulates MMP9 expression in primary myometrium cells. Human primary myometrial cells were transfected with or without $50 \mathrm{nM}$ siRKIP1 or siCONT for $48 \mathrm{~h}$ and then treated with $(A, B) 1 \mathrm{ng} / \mathrm{mL}$ IL1B or (C, D) $10 \mathrm{ng} / \mathrm{mL}$ TNF for an additional $20 \mathrm{~h}$ ( $n=5$ patients). (A, C) MMP9 mRNA abundance was analyzed by qRT-PCR and the fold change was calculated relative to IL1B- or TNF-stimulated siCONT-transfected cells.
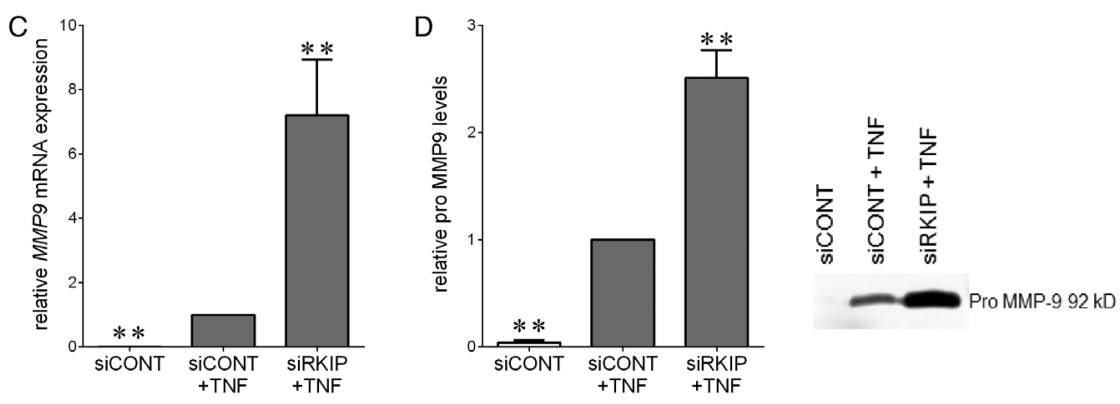

(B, D) The incubation medium was assayed for pro-MMP9 expression by gelatin zymography and the fold change was calculated relative to IL1B- or TNF-stimulated siCONT-transfected cells. Representative gelatin zymography from one patient is also shown. All data are displayed as mean \pm S.E.M. ${ }^{*} P<0.05$ vs IL1B-stimulated siCONT-transfected cells (oneway ANOVA); ${ }^{* *} P<0.05$ vs TNF-stimulated siCONT-transfected cells (one-way ANOVA).

\section{Discussion}

The novel findings of this study are that the expression of RKIP is decreased in laboring myometrium and in response to the pro-inflammatory cytokines IL1B and TNF. Furthermore, a role for RKIP in the genesis of inflammation-induced pro-labor mediators in human myometrial cells is also demonstrated. Specifically, RKIP knockdown by siRNA significantly augmented IL1B- and TNF-stimulated CXCL1 and CXCL8 mRNA expression and release; PTGS2 mRNA expression and subsequent $\mathrm{PGF}_{2 \alpha}$ release and MMP9 mRNA expression and pro-MMPg secretion. These effects appear to be

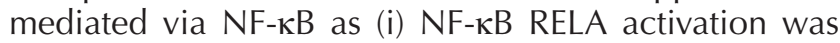
significantly augmented by IL1B or TNF significantly in siRKIP-transfected cells and (ii) in siRKIP-transfected cells treated with the NF- $\mathrm{KB}$ inhibitor BAY 11-7082, IL1B and TNF failed to induce the expression and secretion of pro-inflammatory ad pro-labor mediators.

Inflammation is central to human labor and delivery, both at preterm and term (Christiaens et al. 2008b). In the myometrium, uterus and fetal membranes, there is evidence of leukocyte infiltrate (Thomson et al. 1999, Osman et al. 2003). It is postulated that the invading leukocytes can augment the pro-inflammatory microenvironment through the release pro-inflammatory cytokines such as IL1B and TNF. In support, there is increase in the expression of pro-inflammatory cytokines such as IL1B and TNF at the time of labor (Elliott et al. 2001, Bowen et al. 2002, Tattersall et al. 2008). In this study, treatment of primary myometrial cells with IL1B or TNF significantly decreased RKIP expression. This suggests that the decreased RKIP expression observed in human term laboring myometrium may be a consequence of the increased inflammation in these tissues.
In vitro and in vivo studies have shown that IL1B and TNF can amplify or initiate the process of parturition. For example, intra-amniotic and/or systemic administration of IL1B or TNF to mice and monkeys induces preterm labor (Romero et al. 1991, Romero \& Tartakovsky 1992, Sadowsky et al. 2006). In vitro, they have been shown to increase the production chemokines (e.g. CXCL1 and CXCL8) involved in the recruitment of leukocytes into the intrauterine environment; promote the production of prostaglandins via PTCS2, mediators of uterine contractions; and MMPs which activate cervical ripening and fetal membrane rupture, events culminating in successful labor and delivery (Roh et al. 2000, Bowen et al. 2002, Keelan et al. 2003, Lappas \& Rice 2004, Christiaens et al. 2008b, Tattersall et al. 2008). Additionally, IL1B can induce basal and storeoperated calcium entry in myometrial smooth muscle cells (Tribe et al. 2003), thus directly enhancing their contractile potential. Thus, it was of interest to determine if RKIP regulates pro-inflammatory and prolabor mediators in the presence of IL1B or TNF. siRKIP knockdown in primary myometrial cells was associated with a significant increase in IL1B- and TNF-induced expression and secretion of the chemokines CXCL1 and CXCL8, PTGS2 mRNA expression and subsequent prostaglandin $\mathrm{PGF}_{2 \alpha}$ release and MMP9 mRNA expression and release of pro-MMP9. Collectively, these data indicate that RKIP is important to IL1B and TNF signaling pathways associated with preterm birth.

RKIP has been shown to regulate inflammation via MAPK1 (Yeung et al. 1999, 2000, Li et al. 2014, Huang et al. 2016, Wu et al. 2016). In human myometrial cells, our previous studies have shown that MAPK1 is required for the regulation of inflammation in the presence of IL1B but not TNF (Lappas 2016b). 

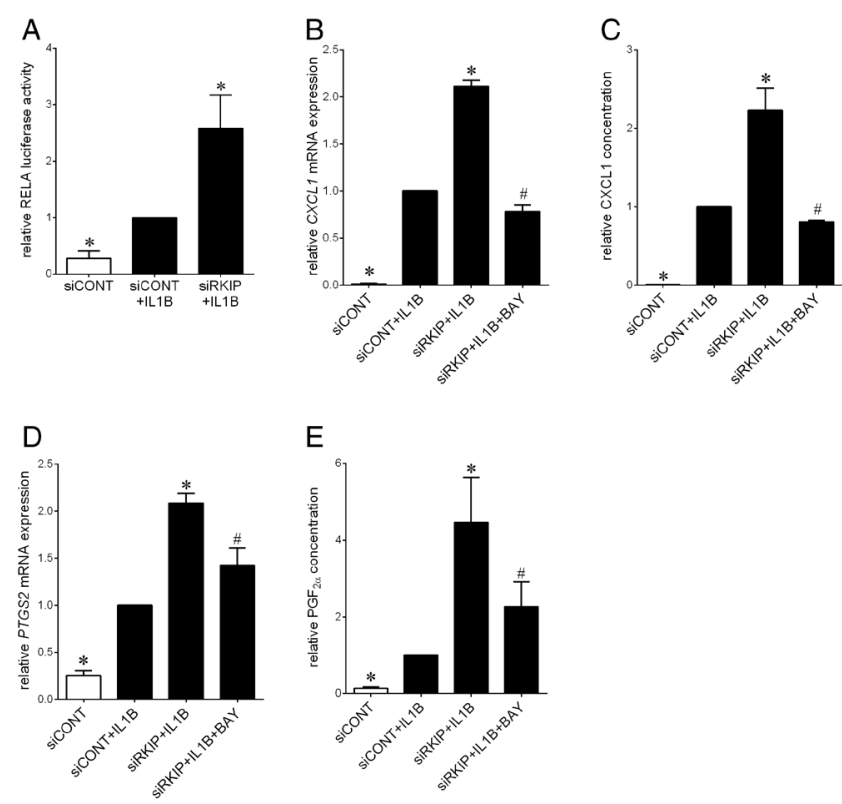

Figure 5 RKIP regulates IL1B-induced expression of pro-inflammatory and pro-labor mediators via NF- $\mathrm{kB}$. (A) Human myometrial cells were transfected with $0.75 \mathrm{ng}$ NF-kB RELA reporter construct. After $6 \mathrm{~h}$, cells were transfected with $50 \mathrm{nM}$ siRKIP or siCONT for $48 \mathrm{~h}$, and then treated with $1 \mathrm{ng} / \mathrm{mL}$ IL1B for an additional $20 \mathrm{~h}(n=5$ patients). Promoter activity (normalized with Renilla expression) is expressed as a ratio of luciferase activity of IL1B-stimulated siCONTtransfected cells. All data are displayed as mean \pm S.E.M. $* P<0.05$ vs IL1B-stimulated siCONT transfected cells (one-way ANOVA). (B-E) Human primary myometrial cells were transfected with or without $50 \mathrm{nM}$ siRKIP or siCONT for $48 \mathrm{~h}$, and then treated with $1 \mathrm{ng} / \mathrm{mL}$ IL1B in the absence or presence of 10 $\mu \mathrm{M}$ BAY 11-7082 for an additional $20 \mathrm{~h}$ ( $n=5$ patients). (B, D) CXCL1 and PTGS2 and MMP9 mRNA abundance was analyzed by qRT-PCR and the fold change was calculated relative to IL1B-stimulated siCONT-transfected cells. (C, E) CXCL1 and PGF $_{2 \alpha}$ concentration in the incubation medium was assayed by ELISA. The fold change was calculated relative to IL1B-stimulated siCONT-transfected cells. All data are displayed as mean \pm S.E.M. $* P<0.05$ vs IL1B-stimulated siCONT-transfected cells (one-way ANOVA); ${ }^{\#} P<0.05$ vs IL1B-stimulated siRKIP-transfected cells (one-way ANOVA).

Thus, it was of interest to determine if RKIP signals through MAPK1 to regulate IL1B-induced inflammation in human myometrium. Interestingly, however, there was no effect of siRKIP on IL1B-induced MAPK1 activation. Furthermore, there was no effect of the MAPK1 inhibitor U0126 on IL1B-induced expression and secretion of prolabor mediators. Collectively, these findings suggest that RKIP does not require MAPK1 to regulate the expression of pro-labor mediators in human myometrium.

RKIP also functions as an inhibitor of NF-KB signaling (Yeung et al. 2001, Tang et al. 2010, Li et al. 2014, Sisto et al. 2014, Wu et al. 2016). NF-kB is a pro-inflammatory transcription factor that has been shown to regulate pro-inflammatory and pro-labor mediators in human myometrium, placenta and fetal membranes in response to IL1B or TNF (Lappas et al. 2002, 2003, Lindstrom \& Bennett 2005, Lappas \&
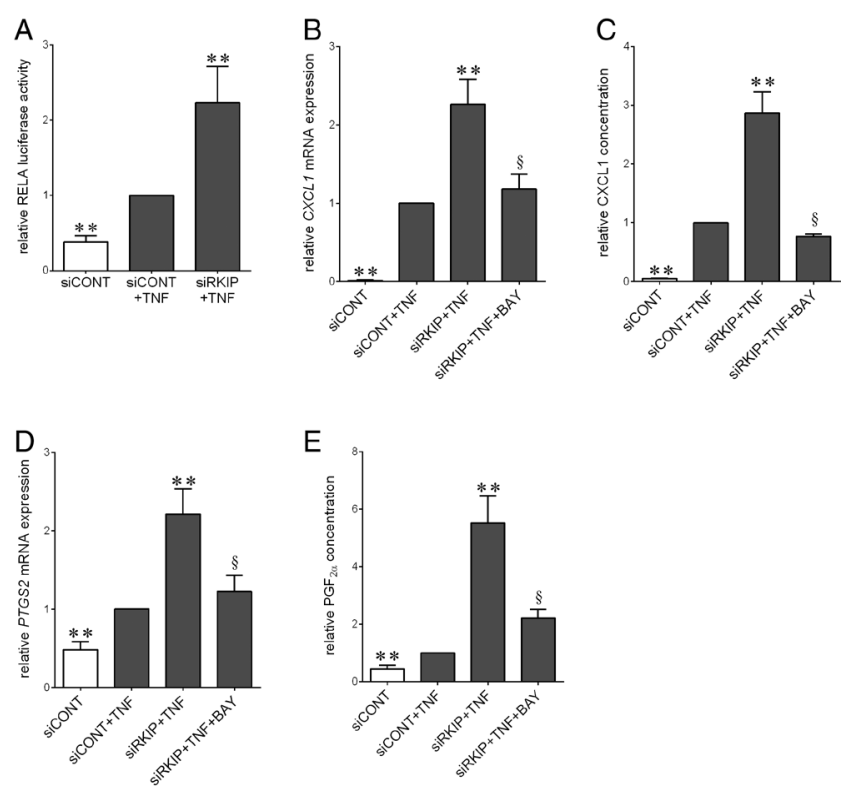

Figure 6 RKIP regulates TNF-induced expression of pro-inflammatory and pro-labor mediators via NF-kB. (A) Human myometrial cells were transfected with $0.75 \mathrm{ng}$ NF-kB RELA reporter construct. After $6 \mathrm{~h}$, cells were transfected with $50 \mathrm{nM}$ siRKIP or siCONT for $48 \mathrm{~h}$, and then treated with $10 \mathrm{ng} / \mathrm{mL}$ TNF for an additional $20 \mathrm{~h}(n=5$ patients). Promoter activity (normalized with Renilla expression) is expressed as a ratio of luciferase activity of TNF-stimulated siCONTtransfected cells. All data are displayed as mean \pm S.E.M. ${ }^{* *} P<0.05$ vs TNF-stimulated siCONT-transfected cells (one-way ANOVA). (B-E) Human primary myometrial cells were transfected with or without $50 \mathrm{nM}$ siRKIP or siCONT for $48 \mathrm{~h}$, and then treated with $10 \mathrm{ng} / \mathrm{mL}$ TNF in the absence or presence of 10 $\mu \mathrm{M}$ BAY 11-7082 for an additional $20 \mathrm{~h}$ ( $n=5$ patients). (B, D) CXCL1 and PTGS2 mRNA abundance was analyzed by qRT-PCR and the fold change was calculated relative to TNF-stimulated siCONT-transfected cells. (C, E) CXCL1 and PGF ${ }_{2 \alpha}$ concentration in the incubation medium was assayed by ELISA. The fold change was calculated relative to TNF-stimulated siCONT-transfected cells. All data are displayed as mean \pm S.E.M. ${ }^{* * P}<0.05$ vs TNF-stimulated siCONT-transfected cells (one-way ANOVA); ${ }^{\S} P<0.05$ vs TNF-stimulated siRKIP-transfected cells (one-way ANOVA).

Rice 2007, Lappas 2016a). In this study, knockdown of RKIP in primary myometrial cells was associated with significantly increased IL1B- and TNF-induced NF- $\kappa B$ RELA transcriptional activity. To determine if RKIP signals through NF-KB to regulate IL1B- or TNFinduced inflammation in human myometrium, an NF-кB inhibitor BAY 11-7082 was utilized. The findings demonstrated that in siRKIP-transfected cells, BAY 11-7082 significantly decreased IL1B- and TNF-induced expression and secretion of pro-labor mediators. Collectively, these findings suggest that, in human myometrium, RKIP acts as a negative regulator of IL1B and TNF signaling by interfering with NF-KB activation.

This study must be interpreted in the context of its limitations. Labor associated in RKIP expression was only assessed in myometrial samples obtained from women at term gestation. The labor-associated changes of RKIP 
should also be assessed at preterm. Furthermore, in vitro siRNA studies in primary myometrial cells were used to show a role for RKIP in regulating inflammation. Animal studies are, however, required to determine if activators or activation of RKIP can prevent inflammation in vivo.

In conclusion, in human myometrium, RKIP expression decreases with term labor and by the proinflammatory cytokines and pro-labor mediators IL1B and TNF. Furthermore, in human primary myometrial cells RKIP negatively regulates IL1B and TNF-induced expression and or secretion of pro-inflammatory and prolabor mediators by inhibiting NF-kB activation. Taken together, the data suggest that regulation of RKIP may constitute a useful therapeutic target for inflammationinduced preterm birth.

\section{Supplementary data}

This is linked to the online version of the paper at http://dx.doi. org/10.1530/REP-17-0006.

\section{Declaration of interest}

The authors declare that there is no conflict of interest that could be perceived as prejudicing the impartiality of the research reported.

\section{Funding}

Associate Professor Martha Lappas is supported by a Career Development Fellowship from the National Health and Medical Research Council (NHMRC; grant no. 1047025). Funding for this study was provided by the NHMRC (grant no. 1058786), Norman Beischer Medical Research Foundation and the Mercy Research Foundation.

\section{Acknowledgements}

The following are gratefully acknowledged: Dr Ratana Lim and Gillian Barker (Obstetrics, Nutrition and Endocrinology Group, Department of Obstetrics and Gynaecology, University of Melbourne) for their excellent technical assistance; the clinical Research Midwives Genevieve Christophers, Gabrielle Pell and Rachel Murdoch for sample collection and the Obstetrics and Midwifery staff of the Mercy Hospital for Women for their co-operation.

\section{References}

Al-Mulla F, Bitar MS, Taqi Z \& Yeung KC 2013 RKIP: much more than Raf kinase inhibitory protein. Journal of Cellular Physiology 228 1688-1702. (doi:10.1002/jcp.24335)

Barros FC, Bhutta ZA, Batra M, Hansen TN, Victora CG \& Rubens CE 2010 Global report on preterm birth and stillbirth (3 of 7): evidence for effectiveness of interventions. BMC Pregnancy \& Childbirth 10 (Supplement 1) S3. (doi:10.1186/1471-2393-10-s1-s3)

Bartlett SR, Sawdy R \& Mann GE 1999 Induction of cyclooxygenase-2 expression in human myometrial smooth muscle cells by interleukin-1beta: involvement of p38 mitogen-activated protein kinase. Journal of Physiology 520 399-406. (doi:10.1111/j.1469-7793.1999.00399.x)

Beck S, Wojdyla D, Say L, Betran AP, Merialdi M, Requejo JH, Rubens C, Menon R \& Van Look PF 2010 The worldwide incidence of preterm birth: a systematic review of maternal mortality and morbidity. Bulletin of the World Health Organization 88 31-38. (doi:10.2471/BLT.08.062554)

Beshir AB, Ren G, Magpusao AN, Barone LM, Yeung KC \& Fenteany G 2010 Raf kinase inhibitor protein suppresses nuclear factor-kappaBdependent cancer cell invasion through negative regulation of matrix metalloproteinase expression. Cancer Letters 299 137-149. (doi:10.1016/j.canlet.2010.08.012)

Blencowe H, Cousens S, Oestergaard MZ, Chou D, Moller AB, Narwal R, Adler A, Vera Garcia C, Rohde S, Say L et al. 2012 National, regional, and worldwide estimates of preterm birth rates in the year 2010 with time trends since 1990 for selected countries: a systematic analysis and implications. Lancet $\mathbf{3 7 9}$ 2162-2172. (doi:10.1016/S01406736(12)60820-4)

Bowen JM, Chamley L, Keelan JA \& Mitchell MD 2002 Cytokines of the placenta and extra-placental membranes: roles and regulation during human pregnancy and parturition. Placenta 23 257-273. (doi:10.1053/ plac.2001.0782)

Christiaens I, Zaragoza DB, Guilbert L, Robertson SA, Mitchell BF \& Olson DM 2008a Inflammatory processes in preterm and term parturition. Journal of Reproductive Immunology 79 50-57. (doi:10.1016/j. jri.2008.04.002)

Christiaens I, Zaragoza DB, Guilbert L, Robertson SA, Mitchell BF \& Olson DM 2008b Inflammatory processes in preterm and term parturition. Journal of Reproductive Immunology 79 50-57. (doi:10.1016/j.jri.2008.04.002)

Elliott CL, Loudon JAZ, Brown N, Slater DM, Bennett PR \& Sullivan MHF 2001 IL-1 $\beta$ and IL-8 in human fetal membranes: Changes with gestational age, labor, and culture conditions. American Journal of Reproductive Immunology 46 260-267. (doi:10.1034/j.1600-0897.2001.d01-11.x)

Erkinheimo TL, Saukkonen K, Narko K, Jalkanen J, Ylikorkala O \& Ristimaki A 2000 Expression of cyclooxygenase-2 and prostanoid receptors by human myometrium. Journal of Clinical Endocrinology \& Metabolism 85 3468-3475. (doi:10.1210/jc.85.9.3468)

Goldenberg RL, Culhane JF, lams JD \& Romero R 2008 Preterm birth 1 - epidemiology and causes of preterm birth. Lancet 371 75-84. (doi:10.1016/S0140-6736(08)60074-4)

Huang QF, Wei L, Liang CH, Nie JL, Lu SJ, Lu CY, Tan SM, Lv SJ, Zhuo L, Lu ZP et al. 2016 Loss of Raf kinase inhibitor protein is associated with malignant progression in hepatic fibrosis. Biomedicine \& Pharmacotherapy 82 669-676. (doi:10.1016/j.biopha.2016.06.007)

Keelan JA, Blumenstein M, Helliwell RJ, Sato TA, Marvin KW \& Mitchell MD 2003 Cytokines, prostaglandins and parturition - a review. Placenta 24 (Supplement A) S33-S46. (doi:10.1053/plac.2002.0948)

Khanjani S, Terzidou V, Johnson MR \& Bennett PR 2012 NFkappaB and AP-1 drive human myometrial IL8 expression. Mediators of Inflammation 2012 504952. (doi:10.1155/2012/504952)

Lappas M 2016a The adaptor protein p62 mediates nuclear factor kappab activation in response to inflammation and facilitates the formation of prolabor mediators in human myometrium. Reproductive Sciences Epub ahead of print. (doi:10.1177/1933719116669058)

Lappas M 2016b RAF1 is increased in labouring myometrium and modulates inflammation-induced pro-labour mediators. Reproduction 151 411-420. (doi:10.1530/REP-15-0607)

Lappas M \& Rice GE 2004 Phospholipase A2 isozymes in pregnancy and parturition. Prostaglandins, Leukotrienes and Essential Fatty Acids 70 87-100. (doi:10.1016/j.plefa.2003.04.001)

Lappas M \& Rice GE 2007 The role and regulation of the nuclear factor kappa B signalling pathway in human labour. Placenta 28 543-556. (doi:10.1016/j.placenta.2006.05.011)

Lappas M, Permezel M, Georgiou HM \& Rice GE 2002 Nuclear factor kappa $B$ regulation of proinflammatory cytokines in human gestational tissues in vitro. Biology of Reproduction 67 668-673. (doi:10.1095/ biolreprod67.2.668)

Lappas M, Permezel M \& Rice GE 2003 N-Acetyl-cysteine inhibits phospholipid metabolism, proinflammatory cytokine release, protease activity, and nuclear factor-kappaB deoxyribonucleic acid-binding activity in human fetal membranes in vitro. Journal of Clinical Endocrinology \& Metabolism 88 1723-1729. (doi:10.1210/jc.2002021677) 
Li B, Sun BL, Zhu JW, Zhou NN, Yang ZP \& Gu JH 2014 Expression of RKIP in chronic myelogenous leukemia K562 cell and inhibits cell proliferation by regulating the ERK/MAPK pathway. Tumor Biology 35 10057-10066. (doi:10.1007/s13277-014-2312-3)

Lim R, Barker G \& Lappas M 2013a A novel role for FOXO3 in human labor: increased expression in laboring myometrium, and regulation of proinflammatory and prolabor mediators in pregnant human myometrial cells. Biology of Reproduction 88 156. (doi:10.1095/ biolreprod.113.108126)

Lim R, Barker G, Wall CA \& Lappas M 2013b Dietary phytophenols curcumin, naringenin and apigenin reduce infection-induced inflammatory and contractile pathways in human placenta, foetal membranes and myometrium. Molecular Human Reproduction 19 451-462. (doi:10.1093/molehr/gat015)

Lim R, Tran HT, Liong S, Barker G \& Lappas M 2016 The transcription factor interferon regulatory factor-1 (IRF1) plays a key role in the terminal effector pathways of human preterm labor. Biology of Reproduction 94 32. (doi:10.1095/biolreprod.115.134726)

Lindstrom TM \& Bennett PR 2005 The role of nuclear factor kappa B in human labour. Reproduction 130 569-581. (doi:10.1530/rep.1.00197)

Liong S \& Lappas M 2015 The stress-responsive heme oxygenase (HO)-1 isoenzyme is increased in labouring myometrium where it regulates contraction-associated proteins. American Journal of Reproductive Immunology 74 62-76. (doi:10.1111/aji.12366)

Norman JE \& Shennan AH 2013 Prevention of preterm birth - why can't we do any better? Lancet 381 184-185. (doi:10.1016/S01406736(12)61956-4)

Osman I, Young A, Ledingham MA, Thomson AJ, Jordan F, Greer IA \& Norman JE 2003 Leukocyte density and pro-inflammatory cytokine expression in human fetal membranes, decidua, cervix and myometrium before and during labour at term. Molecular Human Reproduction 9 41-45. (doi:10.1093/molehr/gag001)

Rauk PN \& Chiao JP 2000 Interleukin-1 stimulates human uterine prostaglandin production through induction of cyclooxygenase-2 expression. American Journal of Reproductive Immunology 43 152-159. (doi:10.1111/j.8755-8920.2000.430304.x)

Roh CR, Oh WJ, Yoon BK \& Lee JH 2000 Up-regulation of matrix metalloproteinase-9 in human myometrium during labour: a cytokinemediated process in uterine smooth muscle cells. Molecular Human Reproduction 6 96-102. (doi:10.1093/molehr/6.1.96)

Romero R \& Tartakovsky B 1992 The natural interleukin-1 receptor antagonist prevents interleukin-1-induced preterm delivery in mice. American Journal of Obstetrics and Gynecology 167 1041-1045. (doi:10.1016/S0002-9378(12)80035-4)

Romero R, Mazor M \& Tartakovsky B 1991 Systemic administration of interleukin-1 induces preterm parturition in mice. American Journal of Obstetrics and Gynecology 165 969-971. (doi:10.1016/00029378(91)90450-6)

Romero R, Espinoza J, Goncalves LF, Kusanovic JP, Friel L \& Hassan S 2007 The role of inflammation and infection in preterm birth. Seminars in Reproductive Medicine 25 21-39. (doi:10.1055/s-2006-956773)

Sadowsky DW, Adams KM, Gravett MG, Witkin SS \& Novy MJ 2006 Preterm labor is induced by intraamniotic infusions of interleukin-1beta and tumor necrosis factor-alpha but not by interleukin- 6 or interleukin-8 in a nonhuman primate model. American Journal of Obstetrics and Gynecology 195 1578-1589. (doi:10.1016/j.ajog.2006.06.072)
Saigal S \& Doyle LW 2008 An overview of mortality and sequelae of preterm birth from infancy to adulthood. Lancet 371 261-269. (doi:10.1016/ S0140-6736(08)60136-1)

Schuierer MM, Heilmeier U, Boettcher A, Ugocsai P, Bosserhoff AK, Schmitz G \& Langmann T 2006 Induction of Raf kinase inhibitor protein contributes to macrophage differentiation. Biochemical and Biophysical Research Communications 342 1083-1087. (doi:10.1016/j. bbrc.2006.02.083)

Sisto M, Lisi S, D'Amore M \& Lofrumento DD 2014 Rituximab-mediated Raf kinase inhibitor protein induction modulates NF-kappaB in Sjogren syndrome. Immunology 143 42-51. (doi:10.1111/imm.12288)

Tang H, Park S, Sun SC, Trumbly R, Ren G, Tsung E \& Yeung KC 2010 RKIP inhibits NF-kappaB in cancer cells by regulating upstream signaling components of the IkappaB kinase complex. FEBS Letters 584 662-668. (doi:10.1016/j.febslet.2009.12.051)

Tattersall M, Engineer N, Khanjani S, Sooranna SR, Roberts VH, Grigsby PL, Liang Z, Myatt L \& Johnson MR 2008 Pro-labour myometrial gene expression: are preterm labour and term labour the same? Reproduction 135 569-579. (doi:10.1530/REP-07-0461)

Thomson AJ, Telfer JF, Young A, Campbell S, Stewart CJ, Cameron IT, Greer IA \& Norman JE 1999 Leukocytes infiltrate the myometrium during human parturition: further evidence that labour is an inflammatory process. Human Reproduction 14 229-236. (doi:10.1093/ humrep/15.1.229)

Tribe RM, Moriarty P, Dalrymple A, Hassoni AA \& Poston L 2003 Interleukin1 beta induces calcium transients and enhances basal and store operated calcium entry in human myometrial smooth muscle. Biology of Reproduction 68 1842-1849. (doi:10.1095/biolreprod.102.011403)

Wu XH, Yang YJ, Xu Z, Li JK, Yang BM, Feng NN, Zhang YS \& Wang SX 2016 Raf kinase inhibitor protein mediated signaling inhibits invasion and metastasis of hepatocellular carcinoma. Biochimica et Biophysica Acta 1860 384-391. (doi:10.1016/j.bbagen.2015.06.009)

Yeung K, Seitz T, Li S, Janosch P, McFerran B, Kaiser C, Fee F, Katsanakis KD, Rose DW, Mischak H et al. 1999 Suppression of Raf-1 kinase activity and MAP kinase signalling by RKIP. Nature 401 173-177. (doi:10.1038/43686)

Yeung K, Janosch P, McFerran B, Rose DW, Mischak H, Sedivy JM \& Kolch W 2000 Mechanism of suppression of the Raf/MEK/extracellular signal-regulated kinase pathway by the raf kinase inhibitor protein. Molecular and Cellular Biology 20 3079-3085. (doi:10.1128/ MCB.20.9.3079-3085.2000)

Yeung KC, Rose DW, Dhillon AS, Yaros D, Gustafsson M, Chatterjee D, McFerran B, Wyche J, Kolch W \& Sedivy JM 2001 Raf kinase inhibitor protein interacts with NF-kappaB-inducing kinase and TAK1 and inhibits NF-kappaB activation. Molecular and Cellular Biology 21 7207-7217. (doi:10.1128/MCB.21.21.7207-7217.2001)

Received 4 January 2017

First decision 31 January 2017

Revised manuscript received 6 February 2017

Accepted 13 February 2017 